Natural Hazards and Earth System Sciences (2003) 3: 693-701

(C) European Geosciences Union 2003

\title{
An historical, geomechanical and probabilistic approach to rock-fall hazard assessment
}

\author{
D. Hantz, J. M. Vengeon, and C. Dussauge-Peisser \\ LIRIGM, Université Joseph Fourier BP 53, F38041 Grenoble cedex 9, France
}

Received: 22 October 2002 - Revised: 18 April 2003 - Accepted: 20 May 2003

\begin{abstract}
A new method (HGP for Historical, Geomechanical and Probabilistic) is proposed to estimate the failure probability of potentially unstable rock masses in a homogenous area, as a function of time. Analysis of a rock falls inventory yields the mean number of rock falls which may be expected in the area for the given time period and a given volume range. According to their geomechanical features, the potentially unstable rock masses are distributed in classes corresponding to different failure probabilities. The expected number of rock falls can be expressed as a function of these unknown probabilities. Assuming that only the ratio between these probabilities can be estimated, combining the historical and geomechanical analysis allows estimating the order of magnitude of the different failure probabilities. The method gives a quantitative significance to the evaluations which are usually attributed to potentially unstable rock masses. Rock-fall hazard can then be compared with other natural hazards, such as floods or earthquakes. The method is applied to a case study of calcareous cliffs in the area of Grenoble, France.
\end{abstract}

\section{Introduction}

Failure on a natural rock slope often generates a very rapid movement propagating far from the source. According to the International Geotechnical Societies' UNESCO Working Party on World Landslide Inventory (UNESCO, 1990) and Cruden and Varnes (1996), these types of movement may be classified as a rock fall, rock topple, rock slide, rock avalanche (type of debris flow) or a complex movement involving several of the former main types. Rock topples and rock slides do not always present high velocity and may be only the early stage of a faster movement. Rock avalanches can occur if the velocity and the volume are large enough to allow a flow-like movement. As rock fall is the most typical

Correspondence to: D. Hantz

(Didier.Hantz@ujf-grenoble.fr) of very rapid rock movements, we use this term to designate all these types of very rapid movements.

Rock-fall hazard results from two processes: detachment of a rock volume from the upper part of the slope (local failure of the slope), and propagation of this volume along the slope. A deterministic evaluation of rock-fall hazard in an extended area would consist of determination of potentially unstable rock volumes, their failure times and their trajectories. Unfortunately, the detailed knowledge of rock slope structure and of failure and propagation processes is not generally sufficient in most areas to make possible such a deterministic evaluation.

Mechanical methods exist to calculate the trajectory of a rock fall or avalanche for a given unstable rock volume (e.g. Hungr and Evans, 1996; Fell et al., 2000; Guzzetti and Crosta, 2001; Labiouse et al., 2001). For individual blocks, the probability to reach a given point with a given energy can be calculated. But it is a conditional probability because it is assumed that the potentially unstable block has gone out from the slope. We will call it the "propagation probability". To get the real "reach probability" of a point, it must be multiplied by the probability of detachment (or "failure probability"), which obviously depends on the considered period (usually of the order of one century for land-use studies).

Probabilistic methods exist to analyse the future stability of designed slopes (Hoek, 1998a; Nilsen, 2000). Most of these methods use Monte-Carlo simulation to obtain the probability for the safety factor to be greater than 1 . But they are not adapted to natural slopes for which one knows that their safety factor is greater than 1 under the present conditions and the question arises of their future evolution. At the present time, no method exists which gives the failure probability of a potentially unstable rock volume as a function of the considered period. The existing methods to evaluate rock-fall hazard in natural slopes give a qualitative and relative evaluation of the failure probability (Cancelli and Crosta, 1993; Hoek, 1998b; Rouillet et al., 1998; Mazzoccola and Sciesa, 2000; Mazzoccola and Sciesa, 2001; Mazzoccola, 2001). 
The purpose of this paper is to propose a new approach to estimate a quantitative probability of failure for potentially unstable rock masses. This approach, called HGP (Historical, Geomechanical, Probabilistic), combines the results of historical and geomechanical analyses to estimate the failure probability (Dussauge et al., 2001; Vengeon et al., 2001; Hantz et al., 2002). Knowing the failure probability of a given rock volume on a slope and the propagation probability to any point downhill, the reach probability at any point could be calculated and compared with the probabilities of other natural hazards like earthquakes or floods. This comparison may be useful for a comprehensive hazards assessment for land-use policy.

\section{Historical analysis}

The objective of the historical analysis is to estimate the mean number of rock falls, which may be expected in a given area, during a given period and within a given volume class. This is possible where an exhaustive inventory of rock falls and their volumes is available for a homogeneous area (from a geological and geomorphological point of view). Inventories may be available from road, railway or forest services, or from natural parks (e.g. Wieczorek et al., 1992; Hungr et al., 1999; Dussauge-Peisser et al., 2002). Some inventories cover periods as long as one century. The larger the considered volumes are, the longer the observation period or the broader the area must be. For small rock falls on a road, significant values may be drawn from some years of observation. For example, 423 rock falls have been observed during a 4year period, on a $11 \mathrm{~km}$ section of road, in La Réunion island (CFGI, 2000); on the other hand, 33 rock falls between 100 and $1000 \mathrm{~m}^{3}$ have been reported in 65 years, along $120 \mathrm{~km}$ of cliff in the Grenoble area (discussed later in detail).

\subsection{Time distribution of rock falls}

The number of rock falls yielded by the historical analysis, for an observation period of length $T_{0}$, must be regarded as an estimate of the mean value of a random variable. Considering that the rock falls are rare, independent and discrete events, the Poisson law applies to describe this variable, as for the frequency of earthquakes. Assuming a Poisson law, the probability that $n$ rock falls occur in a period of length $T_{0}$ is

$$
P\left(n, T_{0}\right)=e^{-\mu\left(T_{0}\right)} \mu\left(T_{0}\right)^{n} / n !
$$

$\mu\left(T_{0}\right)$ being the mean number of rock falls for a period of length $T_{0}$.

The rock fall frequency, for the examined volume interval and the given area, is given by

$f=\mu\left(T_{0}\right) / T_{0}$

and the return period by

$\tau=1 / f$
For a future period of length $T$, the mean number of rock falls will be

$\mu(T)=f T$

and the probability that $n$ rock falls occur in this period

$P(n, T)=e^{-\mu(T)} \mu(T)^{n} / n !$

or

$P(n, T)=e^{-f T}(f T)^{n} / n !$

Note that $P(k n, k T) \neq P(n, T)$, where $k$ is an arbitrary constant.

The probability that at least one rock fall occurs in a period of length $T$ is obtained by summation on $n$ of the Expression (6)

$P(n>0, T)=1-e^{-f T}$

If $f T \ll 1$,

$P(n>0, T) \cong f T$

The use of the Poisson law and the extrapolation from the past to the future supposes a steady state condition for the processes inducing rock falls. Among the different factors influencing rock falls, human activity and climatic conditions may have changed during one century; but it is assumed that the influence of these variations can be neglected regarding the uncertainty of the method, and that the order of magnitude of the rock-fall frequency is not altered over the examined century. This would not be the case if a period with very different climatic conditions was considered (period including immediate post glacial conditions, for instance). Also it is assumed that the occurrence of rock falls does not modify significantly the global geological and geomorphological conditions of the slopes in the studied area. It would not be the case, for example, for a freshly excavated slope, where more rock falls can be expected in the first months, inducing a decrease of the slope angle and an increase of the stability. Such a transient state may have occurred during melting of Würm glaciers. In addition, sites of recent large rock falls commonly generate many smaller rock falls in the days and months following a large event, consequently these individual rock falls should not be considered or counted separately in the probabilistic analysis. Also pre-failure rock falls should not be considered.

\subsection{Volume distribution of rock falls}

The volume frequency distribution of the rock falls have been studied by some authors (e.g. Wieczorek et al., 1992; Hungr et al., 1999; Dussauge-Peisser et al., 2002). For the inventories which have been analysed, the cumulative distribution of rock-fall volumes follows a power law in a volume range covering at least 4 orders of magnitude:

$f(V)=a V^{-b}$

where $f(V)$ is the frequency of rock falls with a volume greater than $V$, and $a$ and $b$ are constants. According to the 


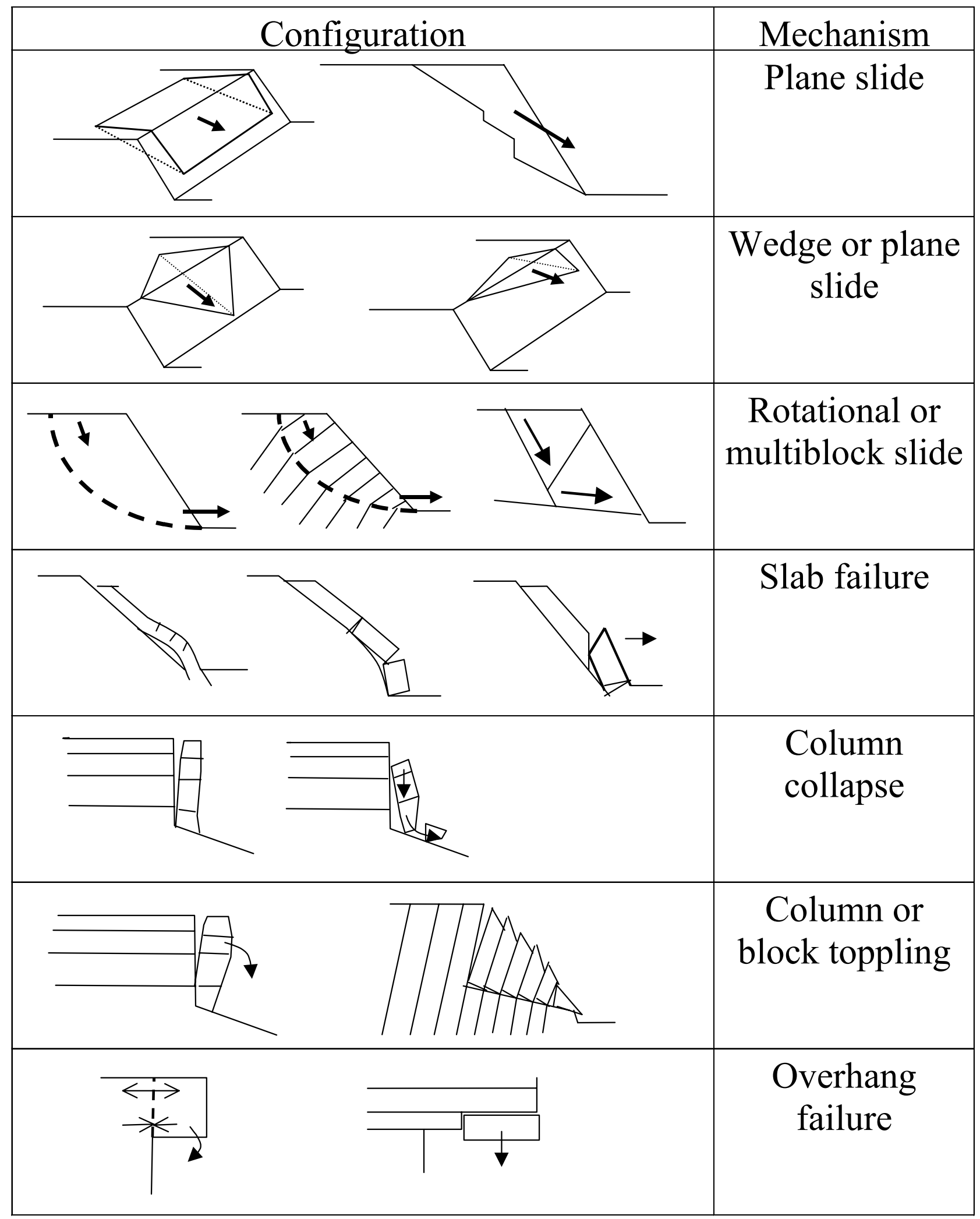

Fig. 1. Typical failure configurations used for identification of potentially unstable rock masses. 


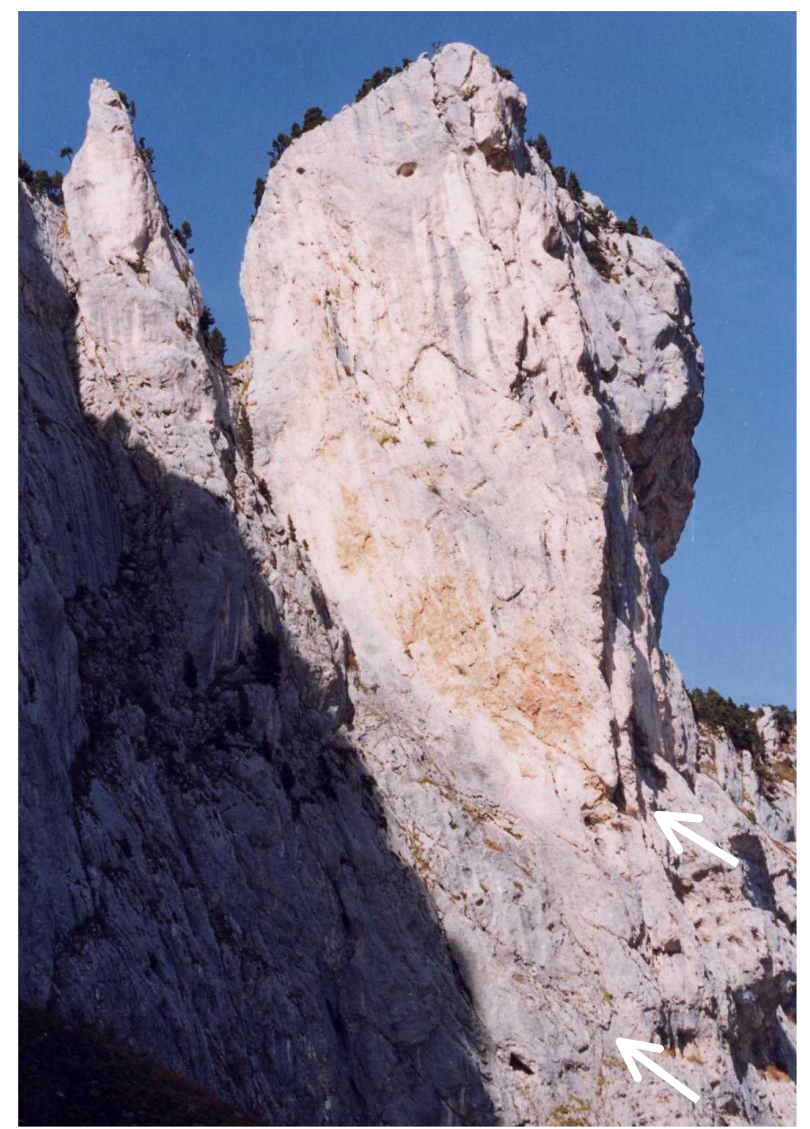

Fig. 2. Example of a potential rock slide in Grenoble area (height: $130 \mathrm{~m}$; volume: $350000 \mathrm{~m}^{3}$ ); potential sliding planes are shown by the arrows. Smaller potential rock falls are visible on the upper right (overhangs).

inventory, $b$ varies between 0.4 and 0.7 whereas a is the frequency of rock falls with a volume greater than $1 \mathrm{~m}^{3}$, supposing that the power law is valid down to this value. $a$ depends on the cliff area examined by the inventory and on the activity of the processes causing the failure of rock masses. To compare different areas, we define the specific rock-fall frequency, as the number of rock falls with a volume greater than $1 \mathrm{~m}^{3}$, per century and per unit cliff area $\left(\mathrm{hm}^{2}\right)$. This specific frequency varies by at least 2 orders of magnitude according to the geological and geomorphological contexts (Dussauge-Peisser et al., 2002). Assuming that the power law reflects physical processes, fitting the observed frequencies to a power law must give better estimates of the mean frequencies. Moreover, if the law was valid outside the observed volume range, extrapolations would be possible, notably for the biggest volumes, which necessitate very long observation periods.

The historical analysis yields a mean number of rock falls which may be expected in a given area, during a given period and within a given volume class, but it does not give the location of these rock falls. Location of potential rock falls can be obtained by the geomechanical analysis.

\section{Geomechanical analysis}

The objective of the geomechanical analysis is to detect potentially unstable rock masses (or potential instabilities) and to classify them according to their failure probability in a given estimation period. The word "geomechanical" means that the analysis is based on the parameters which determine the mechanical behaviour of a rock mass, but it may include qualitative expert evaluation, statistical analysis as well as stability analysis. It must be emphasised that, for financial reasons, the geomechanical survey which can be realised for hazard analysis in a large area can not be as complete as for study of a single slope. Moreover, the uncertainty is often so important that the expert judgement must replace a purely quantitative analysis. Nevertheless this judgement is based on the geomechanical properties of the rock mass. Unlike the geomechanical analysis, the historical approach considers only the volume of the rock falls and not the causal factors.

\subsection{Detection of potential rock fall sources}

The detection is based on the identification of failure configurations, the most typical of them are represented in the Fig. 1, and on the search for indications of recent or present movements (the term "recent" must be regarded in a geological sense and refers to an age up to one century). The objective is to localise and to define, as precisely as possible, potentially unstable rock masses, which then will be individually evaluated. Size and shape of these potentially unstable rock masses depend largely upon joint orientation, extension and spacing. An example of a potentially unstable rock mass is shown in Fig. 2. Each rock mass, called "localised potential instability", must be characterised by its total volume and the dimensions of the individual blocks it consists of.

According to the nature of the slope or the investigation method, it may be impossible to identify localised instabilities, but only to detect the possibility that potentially unstable rock masses exist in a given area of the slope under study. These "diffuse potential instabilities" can be detected by comparing the geological structure of the rock mass and the topography of the slope. This principle of detection was given by Hoek and Bray (1981) for a slope defined by an inclined plane and a horizontal upper surface, and by Goodman and Shi (1985) for the general case of a slope defined by several planes. The detection may be automated by using Geographical Information Systems (e.g. Tanays et al., 1989, 1992; Jaboyedoff et al., 1999).

\subsection{Factors influencing failure probability of a potentially} unstable rock mass

If recent movements are documented, then the probability of detachment of the moving rock mass is usually considered as high. According to the velocity, an evaluation for the short term, and not only for mapping, may be necessary. It must be based on monitoring of the slope. The methodology for in- 
terpretation of monitoring data is out of the scope of this paper (see Rochet, 1992; Azimi and Desvarreux, 1996; Hantz, 2001). Without monitoring, opening of tension cracks is an indication of movement. Increasing block-fall frequency may indicate slow movement of a larger rock mass.

The evaluation of the failure probability of presently stable rock masses is more difficult (why would they become unstable and when?). As illustrated on the Fig. 3, the failure may be due to a decrease of the rock mass strength, an increase of the active stresses or both of these phenomena. These variations can be induced by human activities, which are normally predictable, or by natural processes. These latter may be continuous and progressive (and theoretically detectable) or discontinuous and uncertain. Of course, the present state of stability also influences the failure probability for a future period: the higher the present stability, the lower the failure probability. The factors that have to be considered in the evaluation of the failure probability of a presently stable rock mass may be classified in four categories: present state of stability; continuous natural processes; discontinuous and uncertain natural processes; human modifications of the slope.

Theoretically, the present state of stability can be analysed with a classical stability analysis (limit equilibrium methods are frequently used) and quantified by means of a safety factor. In most cases, the present state of stability depends mainly upon the joint conditions: Extension, percentage of rock bridges, roughness, opening, infilling. Despite the important uncertainty that affects the involved parameters, stability analyses are largely used for rock slope design, in a deterministic or probabilistic way. In the deterministic approach, the uncertainty is coped with by requiring a value greater than 1 for the safety factor (1.5 for example) and accordingly modifying the slope. In the probabilistic approach, the slope is designed in order to reach an accepted failure probability. On the contrary, in rock slope evaluation, the slope has to be considered in its actual state and the uncertainty remains. Moreover, the knowledge of the present safety factor of a slope (or its probability distribution in the probabilistic approach) is not sufficient to evaluate the failure probability according to the considered period (Fig. 3).

Continuous natural processes that can decrease the stability are weathering and dissolution, repeated freeze-thaw, damage due to repeated subcritical stresses, permafrost retreat, erosion, accumulation of material, tectonic deformations. These processes act at a geological time scale and with very low rates, which make them difficult to observe and quantify.

Discontinuous natural processes susceptible to produce failure are earthquake vibrations, water pressure, freeze thaw or water content increase, rapid erosion or accumulation. (They are induced by external exceptional events such as heavy rainfall, rapid thaw, earthquake or debris flow). Seismologists or hydrologists can determine the occurrence probability of some of these events, but their influence on the slope is difficult to quantify. For ground water, the flow pattern in rock masses is poorly known and quantitative analysis

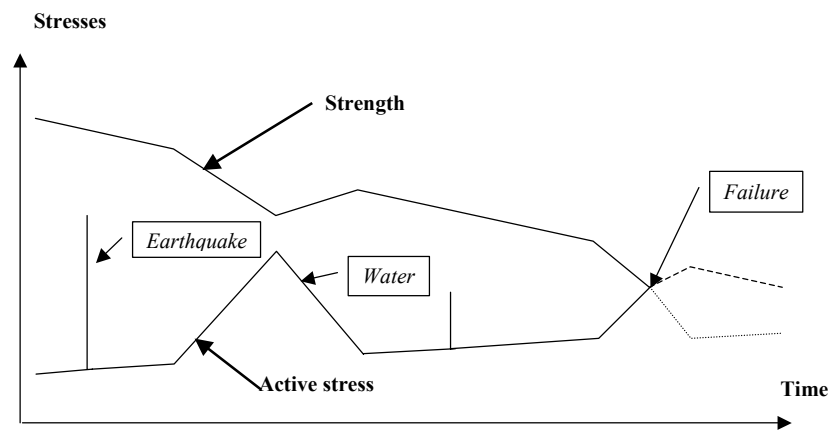

a. Failure triggered by a discontinuous and uncertain process (water pressure increase)

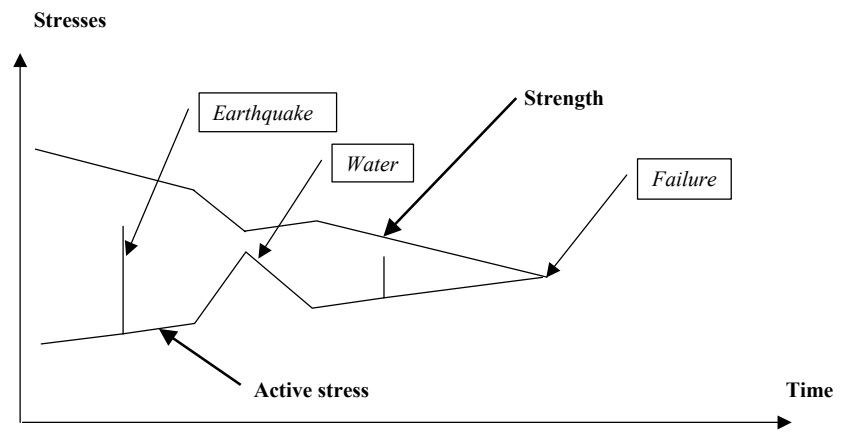

b. Failure due to continuous processes (decrease of rock mass strength and increase of the active stress)

Fig. 3. Illustration of processes leading to failure of a potentially unstable rock mass.

is highly uncertain. The influence of earthquakes on slopes is better understood and dynamic analyses allow comparing the susceptibilities of different potentially unstable rock masses.

Human modifications of the slope may be produced by excavations, blasting vibrations, modifications of surface or underground water flow. They are normally known and predictable, and can be input for static or dynamic stability analyses.

\subsection{Qualitative evaluation of the failure probability}

Most of the existing methods for failure probability evaluation use the above-mentioned controlling factors to grade the potentially unstable rock masses. Some of them are directly based on expert judgement, and give a qualitative classification (e.g. Effendiantz, 2001). For example, it may consist of three classes corresponding to high, medium and low failure probabilities. Other methods use a weighting of the influencing factors to calculate a hazard index (e.g. Baillifard et al., 2001; Mazzoccola and Sciesa, 2000, 2001; Mazzoccola, 2001). But the attribution of weighted values is based again upon the experts experience and judgement. Quantitative engineering methods (developed for slope design) may contribute in the expert judgement, but they are unable to predict the time evolution of presently stable rock masses. 


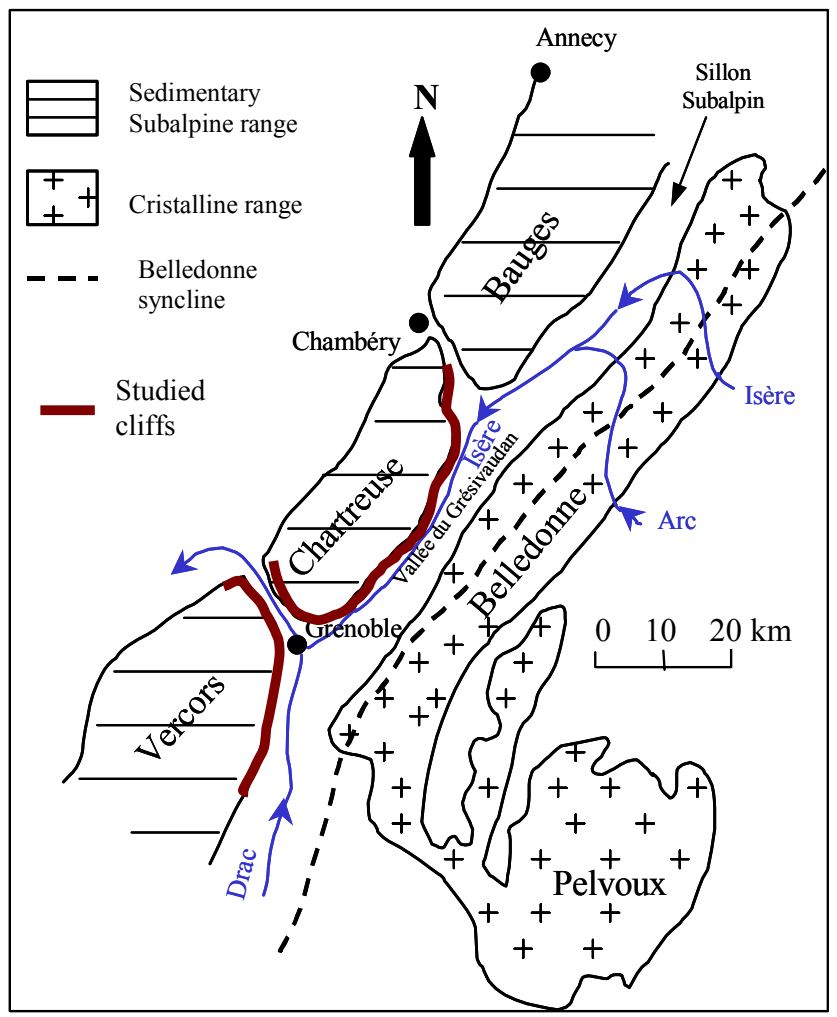

Fig. 4. Location of the studied cliffs in the Grenoble area.

\subsection{Quantitative evaluation of the failure probability}

At the present time, no method gives a true quantitative failure probability for a given potentially unstable rock mass. But one can expect that statistical analysis, similar to the ones which have been developed for landslide hazard assessment (see Carrara et al., 1990; or other references cited by Aleotti and Chowdhury, 1999), will develop in the near future for rock falls. These analyses should give more objective results than the existing classification in high, medium or low failure probability classes.

The new approach proposed in this paper (HGP approach) supposes that the order of magnitude of the ratio $r$ between the probabilities associated to these classes is known. In other words, it supposes that relative failure probabilities can be estimated. If the unknown mean probability corresponding to the higher probability class is $p_{1}$, the mean probability corresponding to the second class is $p_{2}=p_{1} / r$.

Note that the expected mean number of rock falls in the studied area, for the estimation period (of length $T$ ) and the considered volume class, is

$\mu(T)=\sum n_{i} p_{i}$

where $n_{i}$ is the number of potential rock falls in the class $i$.

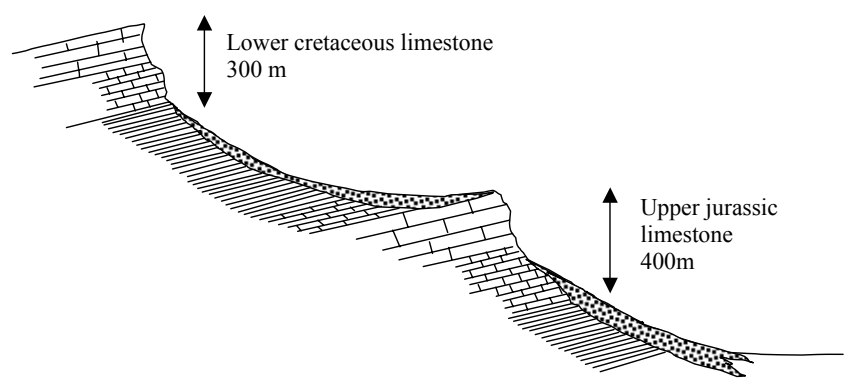

Fig. 5. Typical cross section of the cliffs in the Grenoble area.

\section{Historical-geomechanical-probabilistic (HGP) approach}

In this presentation of the HGP approach, it is assumed that the potentially unstable rock volumes detected in the studied area, in a given volume class, have been classified in 3 probability classes, according to the above-described principle.

The unknown failure probability $p_{1}$ may be obtained by equating the Expressions (4) and (9), with the condition $p_{i} \leq$ 1 . The obtained equation is

$\sum n_{i} p_{i}=f T$

and the solution is

$p_{1}=f T r^{2} /\left(n_{1} r^{2}+n_{2} r+n_{3}\right)$

If the obtained value for $p_{1}$ is greater than 1 , it means that the geomechanical analysis is not compatible with the historical one. In other words, it means that the geologist has not found enough potential rock-fall sources to be in agreement with the historian, or that the hypothesis of a steady state for the global rock-fall process is not valid. But the number of possible failures recognisable in the field is usually much higher than the historical failures. In the simple case where there is only one probability class, it is obvious that the number of detected potential rock-fall sources must not be too small compared with the expected mean number of rock falls. It must be kept in mind that $r T$ is the expected mean number of rock falls for the evaluation period and that the real number of rock falls which will occur may differ from this mean value, according to the Poisson law. Moreover, the method can give only an order of magnitude of the failure probability. Consequently, only if $p_{1}$ is clearly greater than 1 , can the geomechanical analysis be considered incompatible with the historical one.

Note that the question of the failure probability is relevant especially for large rock falls. These ones are sufficiently scattered so that areas with very different failure probabilities can be differentiated on the slopes, and, consequently, areas with very different reach probabilities can be differentiated downhill. This grading is very important for land-use policy. Moreover, the knowledge of the order of magnitude of the rock-fall reach probability allows comparison of rock- 
Table 1. Observation period, number of observed rock falls, observed class frequency and cumulated frequency (per century), calculated cumulated frequency and class frequency (assuming a power law distribution) for each volume class (calcareous cliffs in the Grenoble area)

\begin{tabular}{lccccc}
\hline Volume class $\left(\mathrm{m}^{3}\right)$ & $10^{2}-10^{3}$ & $10^{3}-10^{4}$ & $10^{4}-10^{5}$ & $10^{5}-10^{6}$ & $10^{6}-10^{7}$ \\
\hline Observation period & $1935-2000$ & $1935-2000$ & $1935-2000$ & $1800-2000$ & $1600-2000$ \\
\hline Rock fall number & 33 & 9 & 6 & 3 & 2 \\
Observed frequency (per century) & 51 & 14 & 9 & 1.5 & 0.5 \\
Observed cumulative frequency (per century) & 76 & 25 & 11 & 2.0 & 0.5 \\
Calculated cumulative frequency (per century) & 91 & 26 & 7 & 2.1 & 0.6 \\
Calculated frequency (per century) & 65 & 18 & 5 & 1.5 & 0.6 \\
\hline
\end{tabular}

fall hazard with other natural hazards and management of the different hazards in a coherent way.

On the contrary smaller rock falls (single block falls) are often so dense that it is difficult to find areas where the reach probability is low. Because, if a point is threatened by several potentially unstable blocks, the probability, for this point, to be reached by at least one block is the sum of the reach probabilities of each potentially unstable block. In that way, a probability of one can be obtained easily, especially for long periods. The relevant question is then to know the energy of the blocks, in order to design mitigation works. This question is answered by propagation studies, but the altitude and energy distribution of the trajectories along the slope significantly differs according to the method used (Labiouse et al., 2001).

\section{Case history}

The HGP approach is being tested in the Grenoble area (French Alps), where $120 \mathrm{~km}$ of cliffs are being studied to evaluate large rock-fall hazard during the next century (Fig. 4). The considered volumes are of the order of $100000 \mathrm{~m}^{3}$ or more. The cliffs consist mainly of Thitonian, Valanginian and Urgonian limestone strata that are usually slightly inclined into the slope (Fig. 5). Their height varies between 50 and $450 \mathrm{~m}$. Paleogeographic studies (Arnaud, 1979) have shown that the Urgonian strata have retreated of about $15 \mathrm{~km}$, since they have been submitted to erosion (they initially extended eastward to the Belledonne syncline, shown in Fig. 4). The fact they are relatively rectilinear after such a retreat suggests a uniform retreat rate. Consequently, the studied area can be considered relatively homogenous from a geological and geomorphological point of view.

\subsection{Historical analysis}

A rock-fall inventory for the Grenoble area has been made by a forest service (RTM, 1996), which have recorded rock falls occurring before and during the 20th century, which have left physical or historical traces. The inventory comprises about one hundred rock falls having occurred in the four last centuries. The exhaustiveness of the inventory depends on the volume class. The bigger rock falls have left traces, which remain visible for several centuries. So the inventory has been assumed to be exhaustive for the 4 last centuries for the volume class from 1 to $10 \mathrm{hm}^{3}$, and for the 2 last centuries for the volume class 0.1 to $1 \mathrm{hm}^{3}$. Considering the last century, rock falls in the class $10 \mathrm{~m}^{3}-100 \mathrm{~m}^{3}$ are less numerous than in the class $100 \mathrm{~m}^{3}-1000 \mathrm{~m}^{3}$. It proves that the inventory is not exhaustive under $100 \mathrm{~m}^{3}$. We assumed that it is roughly complete for the period 1935-2000 and for the volumes between $100 \mathrm{~m}^{3}$ and $100000 \mathrm{~m}^{3}$. The numbers of rock falls for the different volume classes and considered periods are given in the Table 1, with the corresponding "observed" class frequencies and cumulative frequencies. A power law (Eq. 9) has been fitted to the observed cumulative values to give "calculated" cumulative frequencies and class frequencies (Table 1). The parameters of the power law are $a=1122$ and $b=0.55$.

Power law fittings have been realised for different volume ranges and different time periods. Dussauge et al. (2002) found that the power law is accepted by a $\chi^{2}$ test for volumes larger than $50 \mathrm{~m}^{3}\left(\chi^{2}=5.2\right)$. The linear regression and maximum likelihood methods provide similar values for $b$ and for $a$. The standard deviation of the $b$ value have been estimated to 0.11 , using a maximum likelihood method. A sensitivity analysis has shown that varying the $b$ value of 0.1 , with the same $a$ value, induces a variation of the frequency by a factor 5 for the rock falls larger than $10^{7} \mathrm{~m}^{3}$. Consequently, an inventory with 53 events can only give an order of magnitude of the rock-fall frequency for the largest volumes.

\subsection{Geomechanical analysis}

The detection of potential instabilities is mainly based on the stereoscopic observation of aerial photographs of the cliffs, taken at the scale of about 1/3000 with oblique axis. Two sets of photographs were taken, with an axis making an horizontal angle of + or $-30^{\circ}$ with the normal to the cliff. From these photographs, potentially unstable rock masses are detected according to the typical failure configurations described in Fig. 1 (an example of a potential rock slide is given on Fig. 2). Then each potential instability is investigated during a field survey and the influencing factors mentioned in Sect. 3.2 are 
Table 2. Failure probabilities, in the next 100 years, for 30 potential instabilities distributed in two classes, assuming that 1.5 rock falls are expected in the whole area. Two different relative probabilities (failure probability in the class 1 / failure probability in the class 2 ) and different distributions between the two classes have been considered

\begin{tabular}{ccccc}
\hline $\begin{array}{c}\text { Relative probability } \\
\text { (class 1/class 2) }\end{array}$ & $\begin{array}{c}\text { Number of instabilities } \\
\text { with high probability } \\
\text { (class 1) }\end{array}$ & $\begin{array}{c}\text { Number of instabilities } \\
\text { with low probability } \\
\text { (class 2) }\end{array}$ & $\begin{array}{c}\text { Failure 100-yr } \\
\text { probability for class 1 } \\
\text { potential instabilities }\end{array}$ & $\begin{array}{c}\text { Failure 100-yr } \\
\text { probability for class 2 } \\
\text { potential instabilities }\end{array}$ \\
\hline 10 & 1 & 29 & 0.385 & 0.038 \\
10 & 5 & 25 & 0.200 & 0.020 \\
10 & 10 & 20 & 0.125 & 0.013 \\
10 & 15 & 15 & 0.091 & 0.009 \\
10 & 20 & 10 & 0.071 & 0.007 \\
10 & 25 & 5 & 0.059 & 0.006 \\
10 & 29 & 1 & 0.052 & 0.005 \\
5 & 1 & 29 & 0.221 & 0.044 \\
5 & 5 & 25 & 0.150 & 0.030 \\
5 & 10 & 15 & 0.107 & 0.021 \\
5 & 15 & 10 & 0.083 & 0.017 \\
5 & 20 & 5 & 0.068 & 0.014 \\
5 & 25 & 1 & 0.058 & 0.012 \\
5 & 29 & 0.051 & 0.010 \\
\hline
\end{tabular}

evaluated, in order to qualify its failure probability during the next century. The field investigation includes description of parameters of the joints that delimit the potentially unstable rock masses, particularly of the potential sliding planes. Finally, the experts divide the instabilities in 2 classes, the failure probability associated to the second class being significantly lower than for the first one. As the study is planed for several years, the detection and the classification concerning the total area are not yet completed.

\subsection{Application of HGP method}

To illustrate the HGP method, we have assumed that 30 potentially unstable rock masses have been detected in the volume class $10^{5}-10^{6} \mathrm{~m}^{3}$, in which a mean number of 1.5 rock falls is expected each century. These instabilities have been divided in 2 classes, the probability associated with the second class being 5 or 10 times lower than to the first one. Different distributions of the instabilities between the two classes have been considered. The obtained failure probabilities in the next 100 years, using Eq. (12), are given in the Table 2 . For example, with 10 potential instabilities in the first class, 20 in the second one and a relative probability between them of 10 , the "individual" failure probability is 0.125 for the rock masses belonging to the first class, and 0.013 for the ones in the second class. Depending on the $r$ value and the way the experts distribute the instabilities, the failure probability for the most probable ones (first class) varies from 0.05 to 0.4. These results give the order of magnitude of this probability. It means that the failure of an instability belonging to the first class can be considered as a 1000-year return period event rather than a 100-year return period one.

\section{Conclusion}

The HGP method yields an order of magnitude of the failure probability for potentially unstable rock masses, which have been classified according to geomechanical criteria. This gives a semi-quantitative significance to the qualitative evaluations which are usually attributed to the potential instabilities (e.g. "high, medium or low probability"). By this way, rock fall hazard can be compared with other natural hazards, such as floods or earthquakes, for which 100-year or 1000year return period events can be determined. The method can be used for relatively homogenous area, where a historical rock-fall inventory is available or can be realised. Presently, the weak side of the method is that the relative probabilities result from a subjective evaluation. But improvements are expected from statistical analysis of rock fall data basis, which are planned in several Alpine countries.

\section{References}

Aleotti, P. and Chowdhury, R.: Landslide hazard assessment: summary review and new perspectives, Bull. Eng. Geol. Env., 58, 21-44, 1999.

Arnaud, H.: Paleogeography of the Urgonian limestones of the Southern France, Géobios, Mémoire spécial 3, 363-383, 1979.

Azimi, C. and Desvarreux, P.: Quelques aspects de la prévision des mouvements des terrain, Revue française de géotechnique, 76, 63-75, 1996.

Baillifard, F., Jaboyedoff, M., Rouiller, J. D., and Tosoni, D.: Matterock, Prévention des mouvements de versants et des instabilités de falaises, Programme Interreg II C, 70-84, 2001.

Cancelli, A. and Crosta, G.: Hazard and risk assessment in rockfall prone areas, Proc. Conf. on Risk and Reliability in Ground Engineering, London, 177-190, 1993. 
Carrara, A., Cardinali, M., Detti, R., Guzzetti, F., Pasqui, V., and Reichenbach, P.: GIS techniques and statistical models in evaluating landslide hazard, Earth Surface Processes and Landforms, 16, 427-445, 1991.

CFGI (Comité Français de Géologie de l'Ingénieur): Caractérisation et cartographie de l'aléa dû aux mouvements de terrain, Collection "Environnement - Les risques naturels", Laboratoire Central des Ponts et Chaussées, 2000.

Cruden, D. M. and Varnes, D. J.: Landslide types and processes, in: Landslides, Investigation and Mitigation, National Academy Press, Washington, D.C., 36-75, 1996.

Dussauge, C., Giraud, A., Grasso, J. R., Hantz, D., and Vengeon, J. M.: Historical and geological approach to rock fall hazard assessment, European Geophysical Society, XXVI ${ }^{\circ}$ General Assembly, Nice, Geophysical Research Abstract, 3, GRA 8625, 2001.

Dussauge-Peisser, C., Helmstetter, A., Grasso, J. R., Hantz, D., Desvarreux, P., Jeannin, M., and Giraud, A.: Probabilistic approach to rock fall hazard assessment: potential of historical data analysis, Natural Hazards and Earth System Sciences, 2, 1-13, 2002.

Effendiantz, L.: La méthodologie LPC, Prévention des mouvements de versants et des instabilités de falaises, Programme Interreg II C, 108-114, 2001.

Fell, R., Hungr, O., Leroueil, S., and Riemer, W.: Keynote lecture geotechnical engineering of the stability of the natural slopes and cuts and fills in soil, Proc. GeoEng2000, Melbourne, Australia, $1,2000$.

Goodman, R. E. and Shi, G. H.: Block theory and its application to rock engineering, Prentice-Hall, 1985.

Guzzetti, F. and Crosta, G.: Programma Stone, Prevenzione dei fenomeni di instabilità delle pareti rocciose, Programme Interreg II C, 206-211, 2001.

Hantz, D.: Ingénierie des pentes rocheuses naturelles et artificielles, Les Techniques de 1'Industrie Minérale, 10, 66-75, 2001.

Hantz, D., Dussauge-Peisser, C., Jeannin, M., and Vengeon, J. M.: Danger d'éboulements rocheux: de l'opinion d'expert à une évaluation quantitative - Rock fall hazard: from expert opinion to quantitative evaluation, Symp. Geomorphology: from expert opinion to modelling, Strasbourg, 115-122, 2002.

Hoek, E. and Bray, J. W.: Rock Slope Engineering, The Institution of Mining and Metallurgy, London, 1981.

Hoek, E.: Factor of safety and probability of failure, Rock Engineering, Course notes, http://www.rockeng.utoronto.ca/hoekcorner. htm, 8, 105-114, 1998a.

Hoek, E.: Analysis of rockfall hazards, Rock Engineering, Course notes, http://www.rockeng.utoronto.ca/hoekcorner.htm, 9, 115136, 1998 b.

Hungr, O. and Evans, S. G.: Rock avalanche runout prediction using a dynamic model, Procs. 7th Int. Symp. on Landslides, Trondheim, Norway, 1, 233-238, 1996.

Hungr, O., Evans, S. G., and Hazzard, J.: Magnitude and frequency of rock falls along the main transportation corridors of southwestern British Columbia, Canadian Geotechnical Journal, 36, 224-238, 1999.

Jaboyedoff, M., Baillifard, F., Marro, C., Philippossian, F., and Rouiller, J. D.: Detection of rock instabilities: Matterock methodology, Joint Japan-Swiss Sem. on Impact Load by Rock Falls and Protection Structures, Kanazawa, Japan, 37-43, 1999.

Labiouse, V., Heidenreich, B., Desvarreux, P., Viktorovitch, M., and Guillemin, P.: Etudes trajectographiques, Prévention des mouvements de versants et des instabilités de falaises, Programme Interreg II C, 155-205, 2001.

Mazzoccola, D. and Sciesa, E.: Implementation and comparison of different methods for rockfall hazard assessment in the Italian Alps, 8th Int. Symp. on Landslides, Cardiff, Thomas Telford, 2, 1035-1040, 2000.

Mazzoccola, D. and Sciesa, E.: La metodologia RHAP (Rockfall Hazard Assessment Procedure), Prevenzione dei fenomeni di instabilità delle pareti rocciose, Programme Interreg II C, 84-95, 2001.

Mazzoccola, D.: La metodologia RES, Prevenzione dei fenomeni di instabilità delle pareti rocciose, Programme Interreg II C, 96108, 2001.

Nilsen, B.: New trends in rock slope stability analysis, Bull. Eng. Geol. Env., 58, 173-178, 2000.

Rochet, L.: Mouvements de versants de grande ampleur: auscultation, diagnostic, surveillance, Bull. Eng. Geol. Env., 45, 43-57, 1992.

Rouillet, J. D., Jaboyedoff, M., Marro, C., Philippossian, F., and Mamin, M.: Matterock: une méthodologie d'auscultation des falaises et de détection des éboulements majeurs potentiels, Rapport PNR 31, VDF, Zürich, 1998.

RTM: Inventaire des mouvements rocheux, Secteur de l'Y grenoblois, Rapport du Service de Restauration des Terrains en Montagne de l'Isère, Grenoble, France, 1996.

Tanays, E., Cojean, R., Hantz, D., and Savary, R.: Automatisation de la détection des risques de rupture et de l'évaluation de la stabilité des flancs d'une mine à ciel ouvert, Industrie minérale, les techniques, 3-89, 35-45, 1989.

Tanays, E., Cojean, R., Hantz, D.: A software to design open pit geometry and to draw open pit plans, Int. Journal of Surface Mining and Reclamation, 6, 91-98, 1992.

UNESCO: A suggested method for reporting a landslide, The International Geotechnical Societies' UNESCO Working Party on World Landslide Inventory, Bulletin de l'Association Internationale de Géologie de l'Ingénieur, 41, 5-12, 1990.

Vengeon, J. M., Hantz, D., and Dussauge, C.: Prédictibilité des éboulements rocheux: approche probabiliste par combinaison d'études historiques et géomécaniques, Revue Française de Géotechnique, 95/96, 143-154, 2001.

Wieczorek, G. F., Snyder, J. B., Alger, C. S., and Isaacson, K. A.: Yosemite historical rockfall inventory, U.S. Geol.Surv. Open File Report, 92-387, 38, 1992. 